\title{
International Professional Practice Partnership (IP3) - Overview
}

\author{
Charles Hughes \\ Chairman, IFIP, International Professional Practice Partnership (IP3) Task Force \\ President BCS, 2005-2006 \\ Charles.Hughes@emanagement.ltd.uk
}

\begin{abstract}
The IFIP International Professional Practice Partnership is embarked on the ambitious task of creating an international profession to provide the key leadership in all parts of the global IT industry - both supplier and user sides. Globally, society is utterly dependent on the IT industry for maintaining and enhancing the quality of life in the developed world and the developing world is looking to leverage IT to move rapidly forward. IT is a quintessentially global industry. For example, no e-business user can have any knowledge of where their transactions are processed or their data stored. Only the creation of a strong global profession of qualified and experienced practitioners gives confidence to all users of IT systems that they can trust the systems on which their whole lifestyle depends.
\end{abstract}

Keywords: International Professional Practice Partnership (IP3), IT professionalism, International Federation for Information Processing (IFIP),

\section{Introduction}

The International Federation for Information Processing (IFIP) is a global federation of over 55 member societies and, through its regional affiliates, linking almost 100 national IT bodies with an aggregate membership of almost 1 million individuals. It has as one of its strategic objectives the promotion of a professional approach to IT practice.

This paper sets out the background to the current major initiative and summarises its objectives and achievements to date.

\section{IFIP and Professionalism}

For more than 10 years IFIP has taken a series of actions to promote this objective. The first stage was the creation in the mid 1990s of a Task Force to look at issues 
of Professional Harmonisation. The purpose was to establish a shared understanding of professional practice globally and then to seek to specify a minimum standard. The long term objective being to achieve sufficient formalization to be able to use General Agreement on Trade in Services (GATS) procedures to facilitate mobility of suitably qualified and experienced IT practitioners.

Arising from this work, in 2002, IFIP co-sponsored, with the World IT Services Association (WITSA) and the Organisation for Economic Cooperation and Development (OECD), an international workshop on Global IT Skills Needs. This brought together 35 experts from 14 countries. This conference, entitled "Meeting Global IT Skills Needs - the Role of Professionalism", looked IT skills needs from three angles - demand, supply and constraints. The summary proceedings are available on the internet, [1].

The next step was a meeting hosted by IEEE-Computer Society in Vancouver in late July 2006 to which they invited a number of the world's leading computer societies to meet together with representatives of IFIP to discuss a range of topics of common interest. One strong theme to emerge was the shared interest of the Australian Computer Society (ACS), British Computer Society (BCS) and Canadian Information Processing Society (CIPS) in sharing their mutual experience and practice in promoting and recognizing professional standards among individual IT practitioners. This was followed by a plenary presentation by the then President of the BCS, Charles Hughes, at the World Computer Congress, August 2006 in Santiago, Chile

It was subsequently agreed at the invitation of the IFIP Executive that the three societies would meet again at an early date. The next meeting took place in Cape Town in January 2007 attended by representatives of IFIP, ACS, BCS and CIPS together with the local Computer Society of South Africa (CSSA). At this meeting each society outlined its current progress in promoting professionalism and in recognising suitably qualified and experienced IT practitioners. The societies also agreed to propose to IFIP that it should formally establish a Task Force on IT professionalism. Further, the societies agreed to work together to devise an approach to provide a global minimum standard of individual IT professional practice. This has been designated as International IT Professional (IITP).

The Task Force has since met in London in May 2007, Montreal in September 2007 and Dublin in April 2008.

At its Cape Town meeting the Task Force adopted the name of the International Professional Practice Programme (I3P). However, trademark investigations and other considerations led to the adoption in Dublin in April 2008 of the name International Professional Practice Partnership (IP3).

The remainder of this paper summarises the Task Force's objectives and progress to date. 


\section{IP3 Project}

IFIP's International Professional Practice Partnership (IP3) is working to create an international IT profession, equivalent in prestige to established professions such as law, accountancy and architecture, that will:

- enable organizations to exploit fully the potential of IT;

- be respected by its stakeholders, including employees, employers, customers, academia, governments and key international bodies; and

- be a source of real pride and aspiration for IT practitioners.

IP3 promotes the accomplishments of IT professionals around the world. It is seeking to raise public awareness of the vital role of IT in our modern world and the work of IT professionals in delivering the IT services on which our modern world depends.

\section{What is a Professional?}

One critical step in this process is to provide a well defined and understood method to recognise individual members of this profession. IP3 is therefore preparing a scheme under which any IFIP Full Member or Professional Affiliate body may seek accreditation to recognise their own individual members who have appropriate qualifications and experience as an "International IT Professional" (IITP). Each IITP designated practitioner will be understood to be a trustworthy advisor within the discipline of IT.

The IITP standard will:

- be based on a clear set of criteria establishing a global standard which incorporates the credentials established by accredited national associations;

- be universally recognized, helping enable worldwide mobility for the IT workforce; and

- establish credibility and stature for those who have met its requirements.

However, it will do more. IITP will help ensure that employers have a standardized set of prerequisites for specific IT roles within their respective organizations. This will help professionals and their organizations achieve a higher project success rate, thereby reducing cost overruns and project failure for organizations. They will help to ensure corporate governance in IT, and to help business, government and society gain maximum benefit from IT.

Finally, these credentials will establish professional accountability, governed by a code of ethics and a code of conduct that all those who are accredited must follow.

Those who hold these credentials demonstrate their commitment, expertise, and a desire continually to expand their knowledge. Most important, they demonstrate 
the substantial contribution IT Professionals can bring to organizations worldwide_-because leadership in IT knows no borders.

\section{Accreditation Procedure}

Any IFIP Full Member or Professional Affiliate member can apply to IP3 for accreditation. The member body will be visited by a small party of trained IP3 assessors who will ensure that it has appropriate procedures for assessing applications from individual members for recognition as IITPs.

A fuller discussion of the IP3 Accreditation process will be given later in this session.

IP3 recognises the wide variety of patterns of professional development and regulation around the world. Consequently, IP3 specifies what standards have to be met but leaves to individual bodies the task of demonstrating that those they wish to designate do meet the IP3 criteria. Thus IP3 respects the different practices and traditions that operate in different jurisdictions.

\section{Benefits of an International Standard}

IT is beyond doubt the most international of technologies and industries. While other professions need global standards, no other combines the global reach of IT. IT supply and usage is global, furthermore, the location is unknown to the user. Any e-business user cannot help but be aware that they can have no knowledge of where their details are being transferred to or from where IT services are being provided.

The value of addressing the international challenge through an international organisation such as IFIP is discussed further in Roger Johnson's paper later in this session, [2].

\section{IP3 Membership and Industrial Support}

IP3 is seeking the support of leading IT suppliers and users by giving support, both in cash and kind. The reaction of industry to the IP3 programme has been almost universally supportive.

The Task Force is especially grateful to Microsoft for the considerable support and encouragement they continue to give to the programme. Graham Watson explains the value of IP3 to Microsoft later in this session. 


\section{Conclusions}

Society's utter dependence on IT services in support of almost every aspect of our lives means that we are all dependent on countless IT practitioners and IT systems spread right around the globe. Never has there been a greater imperative to start putting in place standards for all practitioners on whom our society depends wherever in the world they work.

The International Professional Practice Partnership aims to ensure that worldwide suitably experienced and qualified IT professionals can be recognized so that humanity can have confidence that those, individually and collectively, responsible for the IT services can be trusted to deliver the highest quality of service and be held accountable to their peers when they fall seriously short. Only in that way can society be confident of the IT systems on which it is utterly dependent.

\section{References}

1. Meeting Global IT Skills Needs - the Role of Professionalism. Woking, UK, October 2002. Sponsored by IFIP, OECD and WITSA. IFIP, 2002. www.globalitskills.org

2. Johnson, R.G IP3: Member Societies' Role and Engagement. Proceeding of the WCC 2008 Professionalism Conference. 